\title{
Facilitating reef tourism management through an innovative importance-performance analysis method
}

\author{
Alexandra Coghlan* \\ International Centre for Ecotourism Research, Griffith University, Gold Coast, Qld \\ 4222, Australia
}

Please cite this article as: Coghlan, A., Facilitating reef tourism management through an innovative importance-performance analysis method, Tourism Management (2011), doi:10.1016/j.tourman.2011.08.010

\section{Abstract:}

This study presents a quantitative analysis of visitor satisfaction and its relation to tourism attributes on the Great Barrier Reef, Australia. It applies a modified version of the Importance-Performance Analysis to determine various attributes' range of impact on, and asymmetrical contribution to, visitor satisfaction. The analysis of 369 visitor surveys identified a complex relationship between satisfaction and environmental, operational and customer service attributes. It also identified those attributes which have a strong satisfaction-generating potential when they perform well, such as the diversity of the marine life, interactions with other passengers, comfort of the boat, quality of the entertainment, knowledgeable crew, quality of the information provided and the destination of the trip, and attributes with a high dissatisfaction-generating potential when they perform poorly, e.g. customer service, comfort of the trip, weather, quality of the coral, and cost of the trip. The study also considers the use of attribute-based studies of satisfaction within protected area tourism and the management of visitor experiences.

Key Words: marine tourism, sustainable tourism, importance-performance analysis, satisfaction, protected areas. 


\section{Introduction:}

Within the field of tourism in protected areas there have been a number of calls for greater understanding of destination, attraction or service attributes that simultaneously enhance tourist satisfaction and provide useful data to inform the management of protected areas (Doucouliagos \& Hall, 2010). In the past, importance-performance analyses (IPA), particularly those developed in consultation with local tourism stakeholders, have purported to address such knowledge gaps in studies of tourist satisfaction (e.g. Ryan \& Cessford, 2003; Tonge \& Moore, 2007; Wade \& Eagles, 2003). In IPA analyses, visitors to a site are asked to rate how important they felt selected attributes are to their tourism experience, and subsequently to rate how well they felt those same attributes performed. Reviews of IPA studies have questioned the validity and usefulness of the information provided in this way (Deng, 2007, Oh, 2001) and consequently, new approaches have been developed that circumvent some of the issues.

This paper describes the application of an innovative IPA developed by Mikulić and Prebežac (2008) in an airline setting, to a popular protected area tourism attraction, the Great Barrier Reef Marine Park in Queensland, Australia. The rational for selecting the site is based upon the complex internal and external factors that influence management of the reef tourism sector. These factors are described in further detail in the following sections. The findings indicate ways to improve customer satisfaction, whilst taking into account the environmental pressures facing the Great Barrier Reef (GBR), the mindset of the local tourism industry, and the political/management context of the marine park itself. The method proposed here provides an additional tool in managing partnerships between the naturebased tourism industry and natural resource managers that can benefit both business and environmental protection (Bushell \& Eagles, 2007).

As a nature-based tourist attraction, reef tours are considered to be heavily reliant on their environmental condition (e.g. Leujak \& Ormond, 2007; Roman et al, 2007; Uyarra et al, 2009). The reefs that support these tours are however under increasing pressure from human activities such as tourism, over-fishing, coastal development, sewerage discharge, deforestation and farming (e.g. Mora, 2008). In the future, these pressures are likely to increase due to coral reef ecosystems' vulnerability to the effects of climate change, most notably rising sea temperatures and ocean acidification (Hoegh-Guldberg, 2008). Rising sea temperatures lead to bleaching disturbances which are likely to become a chronic stressor in 
many reef areas in the coming decades, and if coral communities cannot recover quickly enough, coral ecosystems are likely to be impoverished (Baker et al, 2008) and potentially less aesthetically-pleasing to tourists who visit them. Based on scientific reports of reef degradation, the reef tourism industry may well be concerned that actual and perceived ecological degradation of coral reefs are likely to affect tourist numbers and the associated economic sectors that rely on healthy reefs for their income (Kragt et al, 2009).

Additional studies of reef tourism suggest that attributes beyond reef health are also important to reef tourists. These other attributes include clear water, warm temperatures, and low health risks (Uyarra et al, 2005), the size of the dive group and the price of the dive (Rudd, 2001; Rudd \& Tupper, 2002), sharing the experience with others and the variety of experiences on offer (Fitszimmons, 2007). Indeed, weather, staff and infrastructure have been shown to be important in the GBR (Coghlan \& Prideaux, 2007; Shafer \& Inglis, 2000). These studies highlight both the mix of attributes that influence visitor experiences and satisfaction, and the need to consider a range of attributes (natural, social and operational) in reef visitor satisfaction studies.

\subsection{Customer satisfaction in tourism.}

The concept of customer satisfaction has been the focus of a number of studies both in national parks and other nature-based settings and in tourism more generally (e.g. Baker \& Crompton, 2000; Fletcher \& Fletcher, 2003; Ryan, 1995; Ryan \& Cessford, 2003). This interest arises out of the intuitive logic that there should be a causal link between quality of a tourism supplier's service, satisfaction and the tourism supplier's success through positive word of mouth and repeat visitation (Baker \& Crompton, 2000). Whilst this study adopts an attribute-based approach, explained in the following paragraphs, it is perhaps useful to note that that nature-based tourism experiences are elusive, and can also benefit from other types of approaches to understanding satisfaction.

The need for more holistic approaches to understanding satisfaction in nature-based tourism arises in part because nature cannot be controlled in the same way as many other attractions. Thus, alternative approaches to understanding and measuring satisfaction are considered particularly relevant in tourism setting that are less structured, such as naturebased tourism, and where services are only one element of the opportunities and experiences provided (Tonge \& Moore, 2007). There has, therefore, been an increasing trend in satisfaction studies to recognise the provider's service quality, affective and 
cognitive components of the broader experience, as well as the role of the tourist him/herself in shaping his or her satisfaction (Baker \& Crompton, 2000; Bigne et al, 2005; Otto \& Ritchie, 1996; Ryan, 2003; Ryan \& Cessford, 2003). Baker and Crompton (2000) for instance stress the links between satisfaction and affective states, saying that "satisfaction refers to an emotional state of mind after exposure to the opportunity" or performance offered by the tourism provider (p.787). The concept of delight, an affective state that combines high arousal, pleasure and the unexpected (Kumar et al, 2001) may provide some useful insights into studies of satisfaction in nature-based tourism that are less controlled and structured.

Whilst the links between service quality and satisfaction require careful attention, particularly less structured attractions and their experiences, there is frequently a pragmatic argument for adopting the attribute-based approach. A pragmatic, attribute-based approach offers two main advantages in a service management context, first, the approach makes sense to managers, and second it allows the outcomes of any management decision to be measured (Ryan \& Cessford, 2003). It is largely recognised that service quality may be considered a causal antecedent of satisfaction, and variables of service quality can be "moderating, interventionist, or act as antecedents in satisfaction" (Ryan \& Cessford, 2003, p.465). In this sense, whilst satisfaction is "purely experiential", reflecting the totality of the experience (Baker \& Crompton, 2000, p.788), it might be said that the presence of high quality tourism attributes facilitates experiencing satisfaction.

An attribute-based approach can therefore provide a useful first step in the analysis of tourist satisfaction, particularly in sectors such as marine-based tourism, which according to Tonge and Moore (2007) is "lagging behind its terrestrial counterparts with a lack of information on [...] satisfaction with the recreational opportunities provided" (p. 769). The attribute-based approach largely arises out of the marketing and service quality literature, based upon gap analyses of between what is expected and what is experienced, or perceptions thereof. One of the most common constructs in satisfaction studies is the expectation (dis)confirmation paradigm, whereby satisfaction is predicated based on how well an attraction, destination or service meets a tourist's pre-purchase expectations (Oliver, 1981). A single measure, or occasionally multiple measures, of satisfaction, along with the performance of certain attributes, is normally collected through Likert-scale questions. This approach allows regression analyses to investigate the effects of attribute performance on subjective measures of tourist satisfaction. 
Baker and Crompton (2000) suggest that visitors may find it easier to respond to questions regarding perceptions compared to disconfirmation questions, and argue that this approach simplifies the task for managers, as perception measures are easier to design and analyse than disconfirmation measures. Given the arguments presented above that consider both the incompleteness of an attribute-based approach, but also its pragmatic value to managers, an attribute-based approach may be considered appropriate if at least two basic conditions are met. First, it must provide useful management implications to tourism practitioners, and second, there must be a recognition that not all service attributes affect satisfaction in the same way.

Given the complexities of understanding satisfaction at a site where the key attraction cannot be controlled in the same way as other sites, where experiences are often less structured and where services are only one element of the opportunities and experiences provided, understanding satisfaction in nature-based tours can present particular challenges. It is not uncommon therefore for nature-based tourism service providers to lament the lack of useful information on visitor satisfaction. Based on a meta-analysis of park visitation and satisfaction studies, the former authors argue that park managers are not provided with enough information with relevant managerial implications (Doucouliagos and Hall, 2010). This become a particularly important issue where the attraction is subject to dynamic conditions such as increasing visitation, changes in environmental states (e.g. climate change) and competing uses. In addition, Fletcher and Fletcher (2003) call for identification of those aspects outdoor recreation that are amenable to being managed and have the strongest relationship to visitor satisfaction. This echoes Ryan and Cessford's (2003) pragmatism and suggests that an attribute-based approach may be most appropriate under some circumstances.

Whilst attribute-based approaches may be very amenable to managers, there are some conceptual pitfalls associated with this approach that must be considered before useful management conclusions can be implemented. In particular, Alegre and Garau (2010) advocate that satisfaction studies must differentiate between dissatisfiers and satisfiers as two separate constructs, not opposite ends of the same continuum. In their study, Baker and Crompton (2000) identified that basic infrastructure attributes may be considered "dissatisfiers" in that their absence or dysfunction can only cause dissatisfaction. They refer to as "satisfiers" those factors that excite, satisfy and motivate visitors. Their absence would not cause dissatisfaction, but lead to a more neutral state about the experience. With regards to protected area tourism, Tonge and Moore (2008) pointed out that the physical 
tourism attributes (e.g. infrastructure), which are commonly associated with dissatisfiers, are easier to manage and therefore dominate satisfaction surveys. On the other hand, satisfiers which are associated with the visitor experience are harder to measure and thus often overlooked. Tonge and Moore (2008) therefore suggest a need for more concerted research attention to experiential satisfiers.

For the purpose of this study, it is proposed that an attribute-based approach with managerial implications for reef tourism stakeholders offers a useful conceptual and practical contribution. The reef tourism sector has the ability to control and manipulate only a limited number of the attributes that influence the reef tourism experience, whilst other salient attributes fall under the remit of protected area managers or natural resource managers. It is therefore critical that tour operators are provided with accurate and meaningful information to guide their operations management, whilst also developing an appreciation of the importance of attributes that rely on other major players in the region (Tyrrell \& Okrant, 2004). In the case of the GBR, reef tourism providers are able to modify attributes such as the comfort of the boat, the interpretive information provided to tourists, and customer service. Managing these attributes may provide interim measures to boost customer satisfaction whilst additional strategies are developed to address issues that fall beyond the scope of individual operators and where change is dependent on the actions of other stakeholders. This study therefore incorporates those attributes that relate to the environmental condition of the reef, as well as those that may be managed by operators.

\subsection{Importance-performance analysis}

To investigate the importance of different attributes to the overall reef tourism experience, this study adopted a quantitative approach based on a modified IPA, following the work of Mikulić and Prebežac (2008). The traditional IPA technique identifies areas of perceived high or low attribute performance combined with high or low attribute importance, providing managers with guidelines to factors that (i) are performing well but need continued investment, (ii) require additional investment as they are underperforming, (iii) are of low priority and require little investment, or (iv) are at risk of overinvestment as they are of low importance to customers. Results are commonly analysed and presented in a grid format such as that presented in Figure 1. 


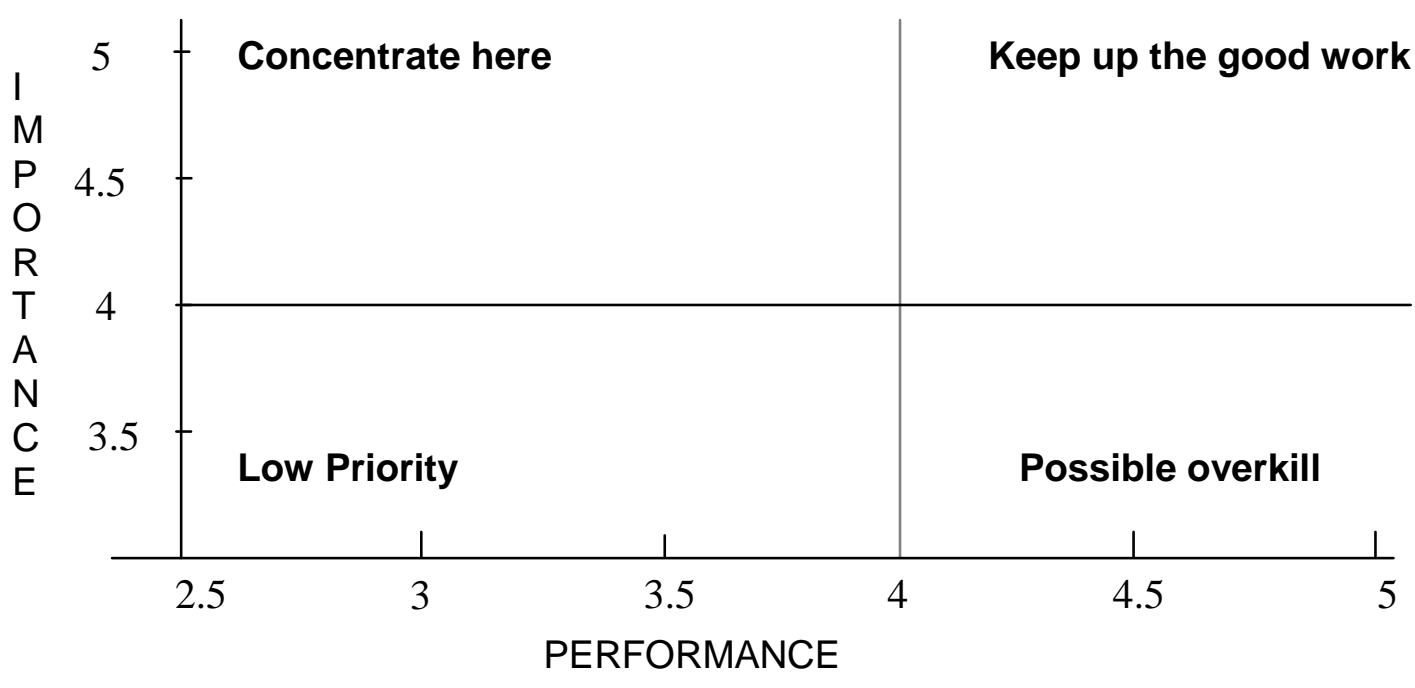

Figure 1: Quadrants used in an importance/performance analysis of service delivery.

This type of approach has primarily been applied to studies of hotel and resort management with some studies of guided tours and destination competitiveness (Chu \& Choi, 2000; Duke \& Persia, 1996; Enright \& Newton, 2004; Evans \& Chon, 1989; Huan et al, 2002; Huang, 2010; Hudson et al, 2004; Pritchard \& Havitz, 2006; Uysal et al, 1991; Weber, 2000; Zhang $\&$ Chow, 2004). IPA studies of protected-area visitor satisfaction have focused on visitor services and accommodation (Hollenhorst et al, 1992; Wade \& Eagles, 2003), facilities, crowding, trial conditions and littering (Ryan \& Cessford, 2003), and environmental, social and managerial conditions (Tonge \& Moore, 2008).

Whilst the usefulness of IPA studies is largely accepted in business management, this type of analysis has nonetheless come under scrutiny regarding the types of assumptions it makes and how the results are interpreted. Tyrell and Okrant (2004) suggest the primary usefulness of IPA may in fact be to facilitate communication between managers and provide organisational focus rather than to compare specific operational changes or investments. It then becomes a tool to discuss organisational goals and operational constraints. Other authors have suggested that the presentation of importance-performance data suffers from a number of limitations that reduce its usefulness to tourism service providers (c.f. Oh, 2001; Bacon, 2003; Deng, 2007; Mikulić \& Prebežac, 2008). Concerns include both the presentation of the information and the theoretical basis of the model. 
Oh (2001) provides a comprehensive review of some of the issues surrounding the IPA technique. Amongst his concerns are the lack of definition of the term "importance", often a multidimensional construct, and no clear differentiation between the notions of importance and expectations, both of which are antecedents of perceptions of performance. Additionally, he suggests that asking respondents to rate the importance of attributes one by one overinflates importance ratings, thereby confusing absolute and relative importance, and reducing the predictive ability of the model. Finally, he questions the relationship between performance and importance, and proposes that there are solid theoretical reasons to believe that importance is positively related to performance, thus skewing how attributes fall within the IPA quadrant. For instance, Oh (2001) cites Ryan and Huyton (2002) who suggest that respondents may base their importance ratings on their travel decisions and the information they receive about the site; in their words "I am told [this place] is important, therefore I think it is important" (p.638).

Additionally, Bacon (2003) identified the positioning of the gridlines as an issue; many attributes may fall in close proximity within the grid, and as researchers separate them to obtain a clearer analysis, the resulting grid may lead to misleading managerial recommendations. He also reiterates that the relationship between attribute-level performance and overall satisfaction can be asymmetric and non-linear so that focussing on a particular attribute may not have the desired effect on improving satisfaction. This view is shared by Deng (2007), who identifies two major areas that must be addressed in future variations of the IPA technique: first, the relationship between attribute performance and attribute importance, and second the relationship between attribute performance and overall satisfaction.

Deng (2007) proposes that deriving attribute importance using a partial correlation analysis between attribute performance and overall customer satisfaction can resolve the issues highlighted above. Using this approach, he builds on Matzler and colleagues' three categories of attribute in relation to satisfaction; basic factors, performance factors and delight factors (Matzler et al, 2004). Developing this approach further, Mikulić and Prebežac (2008) offer a modified IPA to measure the range of an attribute's impact on overall customer satisfaction (OCS), as well as highlight the asymmetrical impact that a particular attribute may have on satisfaction. By modifying the traditional IPA, Mikulić and Prebežac (2008) create measures that quantify the impact of extremely high and extremely low performing attributes on customer satisfaction. They name this measure the Range Impact 
on Customer Satisfaction (RIOCS). They also measure the difference between the Satisfaction-Generating Potential (SGP) and Dissatisfaction-Generating Potential (DGP) in relation to the attribute's RIOCS. In doing so, they arrive at five different categories of attributes (delighters, satisfiers, hybrids, dissatisfiers and frustrators) that may each have a high, medium or low range of impact on customer satisfaction. Whilst their study examined attributes that impact upon airline passenger satisfaction, this study proposes a similar approach to reef tourism, and uses their technique to categorise reef tourism attributes according to their potential to generate satisfaction or dissatisfaction and to establish their level of impact on customer satisfaction.

\section{The Great Barrier Reef as a case study}

The Great Barrier Reef Marine Park is one of Australia's largest tourism attractions, receiving 1.9 million reef visitors, valued at $A \cup \$ 5$ billion, and employing 55,000 people in the region (GBRMPA, 2007). As with other reefs around the world it is subject to a range of environmental pressures from climate change (ocean acidification and increasing water temperatures), extractive uses, pollution, crown-of-thorns outbreaks, diseases, and increasing physical damage from cyclone disturbances (Hutchings et al, 2008). It also faces a number of internal and external drivers from different lobby groups (e.g. conservationists, farmers and fishermen) that influence its environmental management. Finally, its position as a peripheral tourism destination, largely dependent on air travel, within regional Australia adds to the complexity of managing this tourism sector.

As a nature-based tourism attraction, the local industry is clearly concerned at the media reports of reef degradation (Mercer, 2010), and the links between the environmental quality of the Reef and business viability have been highlighted by Huybers and Bennett (2004). However, Dwyer and Kim (2003) point out that it is not so much the real but the perceived environmental quality which influences the buying decisions of potential visitors. Leujak and Ormond (2007) illustrate how changing markets to the coral reefs of the Red Sea influence perceptions of coral quality, as less experienced snorkelers, who have less understanding of and interest in coral health, come to dominate market shares. Whilst the GBR is also characterized by a mass ecotourism market, it is worth noting that longitudinal studies by (authors withheld, in press) reveal a change in visitor satisfaction with their reef experience over the last few years, as well as an increasing awareness of threats to the reef, perhaps as a result of increased attention to the plight of reefs during the International Year of the Reef in 2008. Results from monthly visitor surveys showed significant drop in satisfaction 
scores over the period between January 2007 and June 2010 (when data collection ceased). This may be indicative of an awareness of decreasing environmental quality of the reef.

The decline in reef quality, whilst concerning for many stakeholders, does not appear to be the greatest concern to the tourism industry itself (Wilson \& Turton, 2009). Indeed, Wilson and Turton (2009) report that the industry recognizes that the environmental degradation of the reef is but one factor within a number of concerns (e.g. rising aviation costs, global health scares, the value of the Australian dollar) that might threaten their long-term success. Nonetheless, in the face of decreasing customer satisfaction with the reef tours, it is important to provide industry with recommendations based on quantitative studies of satisfaction. Such recommendations may be used to design interim measures that may help operators buy more time, and assist in building a resilient industry in the face of an uncertain future.

Results may also assist reef tourism sectors and management agencies in other parts of the world who face similar issues, and may be applied more broadly to other nature-based tourism attractions. It must be noted that the GBR holds a number of characteristics, some of which may be shared with other attractions, and others that are unique to the GBR as a tourism attraction. It is an offshore attraction, requiring relatively long and costly transit times, and where operators are simultaneously required to finance and maintain all their access to (vessels) and infrastructure at (pontoons, moorings) the site. On the other hand, tourism providers have little to no ability to manage the natural resources within the marine park, which fall under the remit of protected area managers. Additionally, open-water activities require a number of safety measures prevent water-based incidents whilst the activities themselves may be hampered by poor visibility, waves, currents, seasickness, and potentially dangerous animals. Finally, for guests not venturing into the water, and/or who may not be able to access the semisubmersibles or glassbottom boat tours, there is relatively little visible wildlife. These latter characteristics are relatively unique to the Great Barrier Reef and may or may not apply to other attractions. Indeed, an area of follow-up investigation is the applicability of the method to a broader array of marine and terrestrial nature-based destinations. This will be discussed later in this paper.

\section{Aims:}

The aims of this paper are to apply the innovative importance-performance analysis of Mikulić and Prebežac (2008) to tourism within a marine park, in order to address some of the 
concerns regarding the managerial usefulness of tourism satisfaction studies in protected areas. Specifically, the study aims to identify how various reef tourism attributes influence visitor satisfaction, and in particular identify those satisfaction-generating attributes and dissatisfaction-generating attributes that may be found within the reef tourism experience. This study will also discuss how these may be influenced by operators within the constraints of the regional tourism sector as outlined in the previous section.

\section{Methods:}

The data collected for this study form part of a larger four year study on tourism to the GBR, funded by the Australian government through the Marine and Tropical Sciences Research Facility (MTSRF) under the federal Department of Environmental, Water, Heritage and Arts. Visitor surveys were distributed by the crew of 10 tourism operators in the GBR region in Queensland, Australia. At least one member of the crew of these operators was trained in survey distribution, and the author was present on the first day of data collection to assist with any survey distribution issues as they arose.

A diverse array of operators and locations was selected for this study. This ensured that nearly all the activities offered on the reef are represented. Specific activities covered include pontoon trips, helicopter tours, all SCUBA diving activities (introductory, resort, certified and training), helmet dives, snorkel tours, viewing chambers, semi-submersible tours, glass bottom boat tours, sailing and visiting the islands. Information collected in the surveys includes socio-demographic characteristics of reef visitors, their travel patterns, motivations, activities, previous reef tourism experience and satisfaction, as well as measures of expectations, best and worst experiences, recommendations to others, and value for money (c.f. authors withheld, in press,).

For this specific study, respondents were asked to rate various attributes of their reef trip on a scale of 1 to 5 , where 1 indicated that the attribute had greatly failed to meet their expectations, 3 indicated that it had met expectations, whilst 5 indicated that it had greatly exceeded their expectations. This follows the recommendations of Baker and Crompton (2000) that respondents should assess perceptions of performance quality directly against their expectations through a single measure. From a semantics perspective, a performance measure per se could not always be used, as some of the attributes are outside of the service process, and so the term "performance" may not always be considered appropriate. 
The question therefore read "Based on your trip to the Great Barrier Reef today, please indicate how you rated of each of the following attributes", and for each attribute, e.g. "Diversity of marine life", respondents were given the options : "much worse than expected", "worse than expected", "as expected", "better than expected", "much better than expected".

The specific attributes were selected in consultation with participating operators and based also on previous research (authors withheld) and encompass (i) operational considerations, (ii) customer service aspects of the trip, (ii) environmental interpretation, and finally, (iv) environmental factors. This mix of attributes included some that were under the direct control of the operators, some that they would need improve in partnership with natural resource management groups and others that could not be controlled (e.g. weather). The attributes are listed in Table 1. The attribute-specific questions were added to the general survey over a four month period between March and July 2010. The data were entered into SPSS17, and the impact-range performance analysis and the impact asymmetry analysis were carried according to the procedure described in Mikulić and Prebežac (2008).

Several limitations to this study should be noted. Firstly, the survey distribution and collection was entirely dependent on the cooperation of boat crews. This could lead to concerns over the randomization of sampling, both in terms of respondents and conditions under which distribution occurs (rough/calm seas, no or lots of sunshine, poor/good water clarity). This was particularly apparent when crews were kept very busy in adverse weather conditions, on days when passenger numbers were especially high or when they were shortstaffed or there had been a recent turnover in staffing. Another concern is that some specific markets might not have been captured as the survey was only available in English. This limitation was imposed on the research by partner operators; the surveys were distributed in bulky, water-resistant clipboards and reef tour managers did not want their crew to carry around multiple versions of the survey in several languages. These markets may provide scope for further research to test out the findings of this study in different cultural settings.

\section{Results:}

A total of 369 valid surveys were collected over the four month period. The sample included somewhat more women (58\%) than men (42\%). Over a third of the respondents (35.5\%) came from Australia, a quarter (23.5\%) were from continental Europe, whilst another $17.5 \%$ came from North America, and 16.5\% came from UK and Ireland. Many respondents 
(47.4\%) were aged between 20 and 29 years old, and another $27.5 \%$ were between the ages of 30 to 49 years old. Many were travelling with their partner (37\%) or with friends $(30.2 \%)$. For $74 \%$ of respondents, this was their first visit to the GBR. It should be reiterated that this sample is not necessarily representative of Reef visitors in general.

Several measures of satisfaction with the tour were recorded, including a Likert-scale measure of overall satisfaction, the extent to which the reef and the trip had met pre-trip expectations, and intent to recommend the trip to others. The majority of respondents felt that the reef had largely met their expectations (54\%) or somewhat met their expectations (39\%), and similarly, respondents felt that the trip had largely met their expectations (52.5\%) or somewhat met their expectations (41.5\%). The mean overall satisfaction was just under eight $(7.98$, sd. 0.92$)$ as measured on a scale of one to 10 where 10 indicated very high levels of satisfaction. High levels of overall satisfaction are not uncommon within naturebased tourism (c.f. Pan \& Ryan, 2007; Okello et al, 2008; Akama \& Keiti. 2003). A high percentage of respondents (95\%) said that they would recommend the trip to others.

With regards to the attributes selected for the impact-asymmetry analysis, only three attributes had mean scores over four, indicating that the attributes exceeded respondents' pre-trip expectations (Table 2). These attributes were quality of information provided, with a mean score of 4.05 (sd. 0.89), customer service (4.18, sd. 0.89), and knowledgeable crew $(4.24$, sd. 0.84$)$. The remaining attributes and their mean scores are shown in Table 1, and whilst no other attributes exceeded expectations, there were no attributes that fell below expectations for many respondents.

In the next stage of the analysis, the attributes' range of impact on customer satisfaction were calculated using a penalty-reward contrast analysis (PRCA). In this procedure two sets of dummy variables are created for each attribute. The first set, used to measure the impact of extremely low performance on customer satisfaction (penalty indices), was created by recoding the lowest performance ratings as "1" (Performance $=1$ ), whereas all other ratings were recoded as "0" (Performance $=2,3,4$, and 5). The second set, which was used to measure the impact of high performance on customer satisfaction (reward indices), was created by recoding highest performance ratings as " 1 " (Performance $=5)$, whereas all other ratings were recoded as " 0 " (Performance $=1,2,3$, and 4). A multiple regression analysis 
was then conducted using the two sets of dummy variables as independent variables and customer satisfaction as the dependent variable (Mikulić \& Prebežac, 2008, p.565).

The regression analysis illustrates the effect of very high (5) and very low (1) assessments of performance on satisfaction scores. These results are also shown in Table 1 and again in Figure 2. Low scoring attributes in the RIOCS column had a low impact on customer satisfaction whilst high scoring attributes had a high impact on satisfaction in cases where they performed either very poorly (obtaining a score of 1, i.e. "did not meet pre-trip expectations") or they performed very well (obtaining a score of 5, i.e. "greatly exceeded my pre-trip expectations"). These provide a quantifier for the effect of the attribute on satisfaction, whilst the following calculation, the Impact Analysis Index, indicates the direction of impact on customer satisfaction (Table 2).

Table 1. The trip attributes scored by respondents' according to how well the attribute met pre-trip expectations, $1=$ did not meet expectations at all, $3=$ met expectations, 5 = greatly exceeded expectations. The table also shows the RIOCS values for the 19 attributes.

\begin{tabular}{|l|c|c|c|}
\hline & Mean & $\begin{array}{c}\text { Std. } \\
\text { Deviation }\end{array}$ & RIOCS* \\
\hline Operational attributes & & & \\
Destination of the trip ( $\mathrm{n}=352)$ & 3.62 & 0.894 & 0.119 \\
Interactions with other passengers $(\mathrm{n}=356)$ & 3.52 & 0.851 & 0.149 \\
Length of the trip at the reef $(\mathrm{n}=358)$ & 3.45 & 0.951 & 0.260 \\
Trip length ( $\mathrm{n}=363)$ & 3.25 & 1.049 & 0.102 \\
Cost of the trip $(\mathrm{n}=349)$ & 3.08 & 0.900 & 0.252 \\
\hline Customer service & & & \\
Customer service $(\mathrm{n}=361)$ & 4.18 & 0.890 & 0.253 \\
Quality of the meals $(\mathrm{n}=360)$ & 3.90 & 1.020 & 0.187 \\
Quality of the equipment $(\mathrm{n}=353)$ & 3.81 & 0.974 & 0.161 \\
Comfort of the boat $(\mathrm{n}=362)$ & 3.57 & 0.972 & 0.149 \\
Quality of the entertainment $(\mathrm{n}=308)$ & 3.53 & 0.893 & 0.068 \\
Comfort of the trip $(\mathrm{n}=367)$ & 3.33 & 1.110 & 0.281 \\
Availability of souvenirs $(\mathrm{n}=309)$ & 3.24 & 0.875 & 0.230 \\
Interpretation attributes & & & \\
Knowledgeable crew $(\mathrm{n}=360)$ & 4.24 & 0.847 & 0.055 \\
Quality of the information provided $(\mathrm{n}=365)$ & 4.05 & 0.894 & 0.235 \\
Environmental Attributes & & & \\
Quantity of fish $(\mathrm{n}=364)$ & 3.74 & 1.095 & 0.096 \\
Diversity of the marine life $(\mathrm{n}=360)$ & 3.66 & 1.114 & 0.321 \\
Quality of the coral $(\mathrm{n}=359)$ & 3.63 & 1.119 & 0.376 \\
Visibility in the water $(\mathrm{n}=358)$ & 1.166 & 0.117 \\
\hline
\end{tabular}


Weather $(n=360)$

* Range Impact on Customer Satisfaction

Next, the indices for the attributes' Satisfaction-Generating Potential (SGP), DissatisfactionGenerating Potential (DGP), and Impact Asymmetry (IA) Indices were calculated according to the procedure set out by Mikulić and Prebežac (2008). The DGP values were calculated using the results of the penalty indices regression analysis divided by the RIOCS values shown in Table 1, whilst the SGP values were calculated using the results of the reward indices regression analysis divided by the same RIOCS values. The results are presented in Table 2 and again in Figure 2, where they have been combined with the attributes' RIOCS values to visually present the direction and level of impact of the 19 attributes on customer satisfaction.

Four attributes were found to have a greater DGP than SGP (as represented by their IA value) indicating that they have a greater impact on satisfaction when they perform poorly than when they perform well, and were thus labelled "dissatisfiers". These attributes included the cost of the trip, comfort of the trip, quality of the coral and the weather. A fifth attribute, customer service, was labelled a "frustrator". Frustrators exhibit a particularly high DGP, indicating that in cases of poor performance of the attribute (in this case customer service), visitors are likely to experience greater dissatisfaction than in the case of poor performance of a "dissatisfier" such as the comfort of the trip or the quality of the coral.

A further three attributes were labelled as "hybrids", as their SGP was relatively similar to their DGP. In these cases, their impact asymmetry index value was close to zero, indicating that the performance of these attributes had an equal impact on dissatisfaction when performance was poor as on satisfaction when performance was high. These "hybrid" attributes include the length of the overall trip, the length of time at the reef, and quality of the meals. The remaining attributes were either "satisfiers", e.g. availability of souvenirs, quality of the snorkelling and diving equipment, visibility in the water, and quantity of fish, or "delighters", e.g. interactions with other passengers, comfort of the boat, quality of the entertainment, knowledgeable crew, quality of the information provided, the diversity of the marine life and the destination of the trip.

Another way of interpreting the results provided in Table 2 is that the attributes classified as "satisfiers" have a greater impact in creating satisfaction in cases of high-level performance than they have in creating dissatisfaction in the case of low-level performance. In the case 
of tourism on the GBR, good interpretation, a comfortable boat, and in particular, diversity of marine life all create delight when they are of high quality, but would have less impact on dissatisfaction if they are of low quality. On the other hand, attributes that are classified as "dissatisfiers" all have a greater impact in creating dissatisfaction in cases of low-level performance than they have in creating satisfaction in the case of high-level performance. In the case presented here, weather, customer service and quality of coral all have a stronger impact on dissatisfaction when they are of poor quality, than on satisfaction if they are of high quality.

Table 2: The satisfaction-generating and dissatisfaction generating potential of visitor experience attributes on the GBR, and well as their impact on customer satisfaction.

\begin{tabular}{|c|c|c|c|c|}
\hline \multirow[b]{2}{*}{ Operational attributes } & \multirow[t]{2}{*}{$I A^{4}$} & \multirow[t]{2}{*}{$\left(=\mathrm{SGP}^{2}-\mathrm{DGP}^{3}\right)$} & \multicolumn{2}{|c|}{ Impact on Customer satisfaction } \\
\hline & & & & \\
\hline Destination of the trip & 0.714 & $(=0.857-0.143)$ & Delighter & $\mathrm{IA}>0.4^{*}$ \\
\hline Interactions with passengers & 0.611 & $(=0.805-0.195)$ & Delighter & $\mathrm{I} A>0.4$ \\
\hline Trip length & 0.000 & $(=0.500-0.500)$ & Hybrid & $-0.1<\mid A<0.1$ \\
\hline Length of time at the reef & 0.038 & $(=0.519-0.481)$ & Hybrid & $-0.1<\mid A<0.1$ \\
\hline Cost of the trip & -0.238 & $(=0.381-0.619)$ & Dissatisfier & $-0.1>\mid A>-0.4$ \\
\hline \multicolumn{5}{|l|}{ Customer service attributes } \\
\hline Comfort of the boat & 0.839 & $(=0.919-0.081)$ & Delighter & $\mathrm{IA}>0.4$ \\
\hline Quality of the entertainment & 0.529 & $(=0.765-0.235)$ & Delighter & $\mathrm{I} A>0.4$ \\
\hline Availability of souvenirs & 0.183 & $(=0.591-0.409)$ & Satisfier & $0.1<\mid A<0.4$ \\
\hline Quality of the equipment & 0.391 & $(=0.696-0.304)$ & Satisfier & $0.1<\mathrm{IA}<0.4$ \\
\hline Quality of the meals & -0.134 & $(=0.433-0.567)$ & Dissatisfier & $-0.1>\mid A>-0.4$ \\
\hline Comfort of the trip & -0.231 & $(=0.384-0.616)$ & Dissatisfier & $-0.1>\mid A>-0.4$ \\
\hline Customer service & -0.415 & $(=0.292-0.708)$ & Frustrator & $\mid A<-0.4$ \\
\hline \multicolumn{5}{|l|}{ Interpretation attributes } \\
\hline Knowledgeable crew & 0.418 & $(=0.709-0.291)$ & Delighter & $\mathrm{IA}>0.4$ \\
\hline Quality of information & 0.532 & $(=0.766-0.234)$ & Delighter & $\mathrm{IA}>0.4$ \\
\hline \multicolumn{5}{|l|}{ Environmental attributes } \\
\hline Diversity of the marine life & 0.477 & $(=0.738-0.262)$ & Delighter & $\mathrm{IA}>0.4$ \\
\hline Visibility in the water & 0.179 & $(=0.590-0.410)$ & Satisfier & $0.1<\mathrm{IA}<0.4$ \\
\hline Quantity of fish & 0.292 & $(=0.646-0.354)$ & Satisfier & $0.1<\mid \mathrm{A}<0.4$ \\
\hline Quality of the coral & -0.234 & $(=0.383-0.617)$ & Dissatisfier & $-0.1>\mid A>-0.4$ \\
\hline Weather & -0.390 & $(=0.305-0.695)$ & Dissatisfier & $-0.1>\mid A>-0.4$ \\
\hline
\end{tabular}

Impact Asymmetry Index, ${ }^{2}$ Satisfaction Generating Potential, ${ }^{3}$ Dissatisfaction Generating Potential. ${ }^{*}$ cut-off values of $-0.4,-0.1,0.1$ and 0.4 are based upon the procedure set out by Mikulic and Prebazac (2008) 
The indices shown in Tables 1 and 2 can be cross-referenced to present the information as a chart, where the Impact Asymmetry Index is plotted on the $Y$ axis and the Range of Impact on Customer Satisfaction Index on the $\mathrm{X}$ axis. In this way it becomes possible to look at the managerial implications of the results of the data analysis. For instance, whilst the quality of entertainment might qualify as a "delighter" based upon the strength of its SGP compared to its DGP, it actually has a low impact on customer satisfaction overall, in cases where it performs either very well or very poorly. On the other hand, marine biodiversity is both a delighter and has a very high impact on customer satisfaction, whilst the weather also has a very high impact on customer satisfaction, particularly in cases where it does not meet visitor expectations (Figure 2).

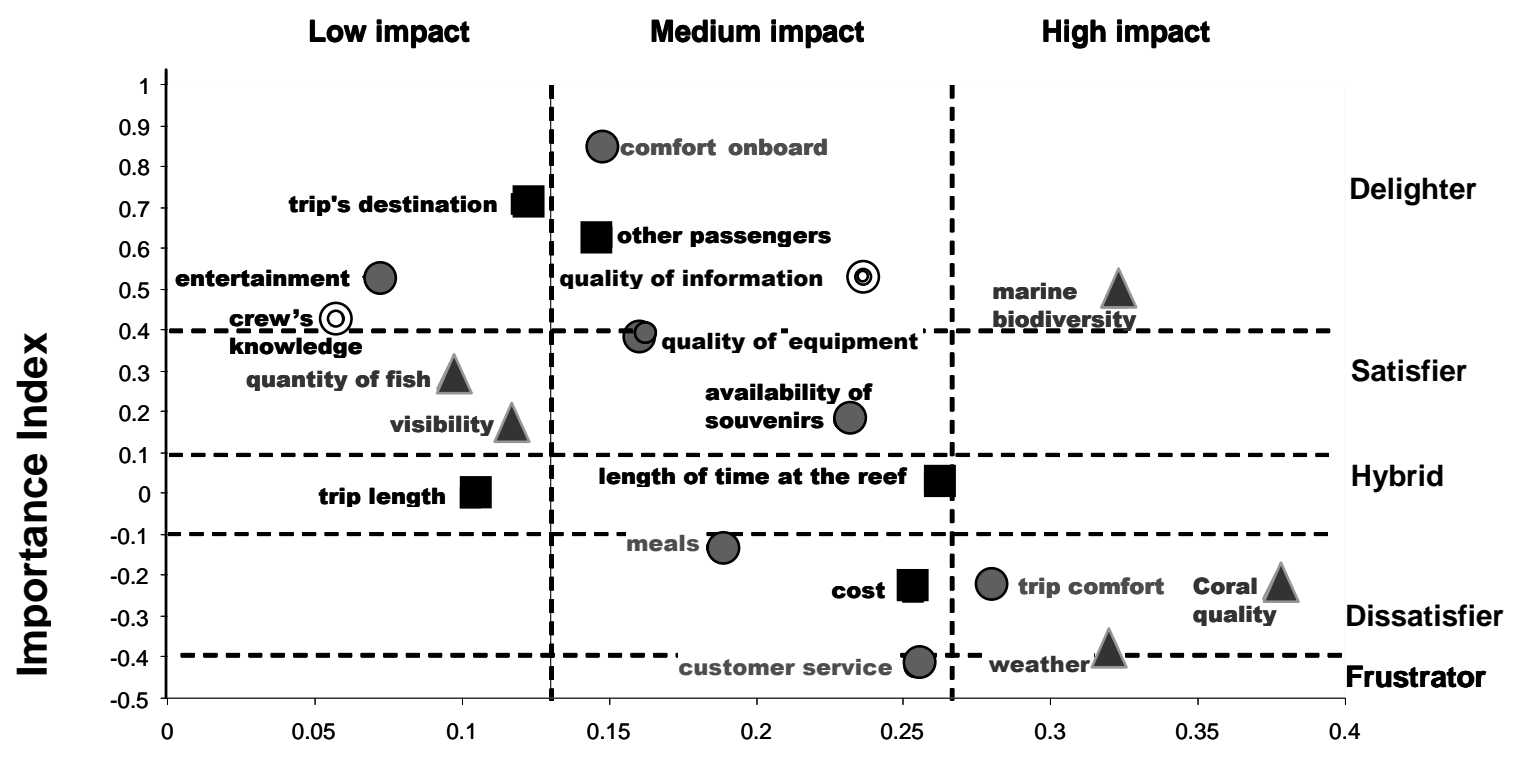

Range of Impact on Customer Satisfaction

Figure 2. Understanding the range of impact and asymmetry of an attribute's impact on customer satisfaction. Points marked with a square indicated operational attributes, with a circle indicate customer service attributes, with a triangle indicate environmental attributes and with a donut indicate interpretation attributes.

\section{Discussion:}

\subsection{Summary of research findings}


The results of this study have revealed several interesting trends regarding reef tourism attributes and visitor satisfaction. It is encouraging to note that none of the attributes were systematically failing to meet visitor expectations. It was clear, however, that attributes could usefully be categorised into "frustrators", "dissatisfiers", "hybrids", "satisfiers" and "delighters" using the IPA approach proposed by Mikulić and Prebežac (2008). Furthermore, by visually presenting the information (Figure 2), it becomes apparent that several attributes outside of the operators' sphere of influence have the highest impact on customer satisfaction, e.g. the weather, the quality of the coral and the level of marine biodiversity.

These attributes include a range of delighters, dissatisfiers and frustrators; for instance marine biodiversity, as a delighter, has a highly positive impact on satisfaction when respondents encountered a range of marine animals, but did not detract greatly from satisfaction when marine biodiversity was not high. On the other hand, the weather (borderline frustrator/dissatisfier) had a highly negative impact on satisfaction when it did not meet expectations, but did not contribute greatly to satisfaction when it did meet expectations. Coral quality followed a similar trend as the weather, suggesting that poor coral quality has a greater impact on dissatisfaction than it does on satisfaction. This is a distinction that has not previously been made in reef tourism studies, suggesting that the environmental condition of coral reefs is important to customer satisfaction to the extent that it underpins marine biodiversity on the reef, a high impact delighter.

This is an important consideration as Mikulić and Prebežac (2008) propose that recommendations for improvements should be based on the range of an attribute's impact on overall customer satisfaction. In their words,

"improvement priority should rise with increasing levels of RIOCS

because this indicates that improved performance would lead to larger

absolute increases in overall customer satisfaction, regardless of whether dissatisfaction decreased or satisfaction increased"

(Mikulić \& Prebežac, 2008, p.564)

\subsection{Management implications: attribute asymmetry, partnerships and substitutability}

This study's managerial implications for the sustainable management of visitor satisfaction in reef destinations may be summarised as follows. First, there is a high level of complexity surrounding the influence of reef tourism attributes on customer satisfaction. Some of the 
results may at first appear counter-intuitive or contradict previous research. For instance low performance of delighters, e.g. marine biodiversity, might not matter as much as low performance of frustrators, e.g. customer service. However, by using the RIOCS values presented in Table 1, it is also clear that the most important attributes rely on partnership with natural resource managers and cannot be addressed by operators acting alone. Indeed, assuring the high quality of two of these important attributes (coral and diversity of marine life) may benefit from the type of partnership between tourism businesses and natural resource managers described by Huybers and Bennett (2004). By providing tourism operators with empirical evidence of the links between high quality natural attributes (in this case, healthy coral and good biodiversity) and tourist satisfaction, reef tourism operators are encouraged to add their support to the conservation measures proposed by natural resource managers and advocate for greater protection of the GBR. In the light of Wilson and Turton's (2009) findings, this is an issue that must be addressed through a co-ordinated effort between scientists, managers and industry (Bohnet, 2010).

Whilst an overall strategy will rely on joint management plan for tourism-relevant reef species, shared resources, and delineation of roles and responsibilities between protected area managers and operators, interim management strategies may focus on attributes with lower RIOCS values and frustrators, such as customer service, trip cost, and the quality of the information provided. Under such circumstances, operators must also be mindful of managing attributes that might have opposing effects on each other, e.g. lowering trip costs may be difficult to achieve whilst simultaneously striving for high customer service and a comfortable trip (often requiring high investments in refurbishment or infrastructure). Additionally, some of the attributes commonly promoted by tour operators in their advertisements, e.g. length of the trip out to the Reef and time spent at the Reef, did not have a strong negative or positive impact on satisfaction, and may not confer any competitive advantage to operators. Given the importance of weather, both as a frustrutor/dissatisfier and its influence tourists' ability to see marine life, additional management measures may be considered to manage poor weather days. One approach, adopted by the whale shark sighting industry in Western Australia, may be to advertise discounted subsequent trips to visitors who had been particularly badly affected by poor weather. Further recommendations include requesting multiple site access and a media communications strategy that manages visitor expectations in the light of current and future environmental uncertainties.

\subsection{Theoretical contributions: satisfaction studies in protected area tourism experiences}


This study also offers new insights into the study of experiences in nature-based tourism attractions, and particularly protected area tourism. Indeed, this study represents the first attempt to examine the range and direction of impact of operational, customer service, interpretive and environmental attributes on visitors' satisfaction in a protected area. The method provides a means to consider both service provisions and other conditions of experience, as called for by Baker and Crompton (2000). This is particularly important, as pointed out by Tonge and Moore (2007), services are only one aspect of the protected area tourism experience. The significance of these results is their ability to provide guidelines for operational management decisions for tourism operators who are facing an increasingly uncertain future as their tourism asset, nature, becomes degraded. This approach suggests both where resources should be allocated as well as whose resources are most relevant. As stated in the introduction, tourism operators have limited control over efforts to conserve and enhance biodiversity but are responsible for the all aspects of the tourism service, limiting the protected area managers' tourism role to administrating and monitoring permits. Indeed, how the tourists themselves understand the relationship between tourism operators and protected area managers, as well as what an experience provider can and cannot control, may also influence the visitor experience and their satisfaction.

The role of the tourist in shaping his or her experience should not be underestimated. Unlike previous studies, where dissatisfiers have been limited to physical attributes, the single largest dissatisfier in this context was customer service. This result may be representative of other ways of understanding the tourist experience, such as Otto and Ritchie's (1996) involvement and recognition factors, or what Ryan and Cessford (2003) describe in their "moments of truth", where a visitor receives "recognition of their individuality that complements an experience of the place" (p.459.). At present attribute-based studies largely ignore the question of how tourists perceive their own role in the production of their experience. Yet results such as the impact of poor customer service do provide clues as to the interpersonal element involved in generating satisfaction and making sense of the experience more generally. This supports the links reported by Baker and Crompton (2000) between performance quality, affective states and satisfaction, and reinforces the role attribute-based studies may perform in the first steps towards an improved understanding of visitor satisfaction.

\subsection{Future research: the dynamic nature of tourist satisfaction in protected areas}


Some additional considerations of using this approach is that changes in one attribute may influence changes in others. This effect was noted by Tyrrell and Okrant (2004) who suggest that interaction terms between attributes be developed to understand how the importance of one attribute may be influenced by the levels of other attributes. This final point certainly represents one area of future research in IPA studies. Further changes in attribute performance, whether driven internally through managerial decisions, or externally through changing circumstances, are likely to shift the positioning of attributes along the IA and RIOCS axes. This is particularly true of nature-based tourism attractions that are dependent upon high environmental quality and are currently under threat. Under these circumstances, a modified IPA can provide operators and natural resource managers with a more sophisticated understanding of how environmental and customer service attributes influence customer satisfaction. This may well address some of the concerns raised by Tonge and Moore (2008) that greater attention should be paid to the experiential attributes in protected area studies. Future research may test a similar approach to terrestrial environments, particularly those areas that are fragile and subject to disturbance, such as alpine areas, coastal regions or rainforest environments.

\section{Conclusion:}

This study has reported on the use of a novel approach to IPA studies, with a particular reference to nature-based tourism and/or protected area tourism. The findings of the study have strong management implications for reef tourism providers, by identifying high and low impact attributes, as well the direction of impact of each attribute. The approach itself is relatively simple to administer; data can easily be compiled by tourism operators, and the final result is at once easy to understand whilst providing sophisticated information on visitor satisfaction, management actions and resource allocations to bolster visitor satisfaction. However, the intermediate step of analysis requires access to statistical packages which operators may not be able to access. The approach therefore requires collaboration with researchers familiar with this approach. Finally, the modified IPA is considered particularly useful for tourism in protected areas, where stakeholders have multiple goals, management resources are shared across a number of actors and tourism services are but one component of the visitor experience. Applying the modified IPA in this way clearly indicates the areas of satisfaction that operators are able to control, those areas in which they must seek assistance to ensure continuing high standards, and those areas where operators must be flexible to compensate for attributes that fall outside the sphere of influence of both 
operators and protected area managers, but nonetheless have a strong influence on tourist satisfaction.

\section{References:}

Akama, J., Kieti, D. 2003. Measuring tourist satisfaction with Kenya's wildlife safari: a case study of Tsavo West National Park. Tourism Management 24 (1), 73-81.

Alegre, J., Garau, J. 2010. Tourist Satisfaction and Dissatisfaction. Annals of Tourism Research 37 (1), 52-73.

Bacon, D.R. 2003. A comparison of approaches to importance-performance analysis. International Journal of Market Research 45 (1), 55-71.

Baker, D.A., Crompton, J.L. 2000. Quality, satisfaction and behavioural intentions. Annals of Tourism Research 27(3), 785-804.

Baker, A. C., Glynn, P. W., Riegl, B. 2008. Climate change and coral reef bleaching: An ecological assessment of long-term impacts, recovery trends and future outlook. Estuarine, Coastal and Shelf Science 80, 435-471.

Bigne, J . E. , Andreu, L ., Gnoth , J . 2005. The theme park experience: An analysis of pleasure arousal and satisfaction. Tourism Management 26, 833 - 844.

Bohnet, I. 2010. Integrating social and ecological knowledge for planning sustainable landand sea-scapes: experiences from the Great Barrier Reef Region, Australia. Landscape Ecology 25, 1201-1218.

Brodie, J., Binney, J., Fabricius, K., Gordon, I., Hoegh-Guldberg, O., Hunter, H., O’Reagain, P., Pearson, P., Quirk, M., Thorburn, P., Waterhouse, J., Webster, I., Wilkinson, S. 2008. Scientific consensus on water quality in the Great Barrier Reef. Reef Water Quality Protection Plan Secretariat; Brisbane.

Bushell, R., Eagles, P. 2007. Tourism and Protected Areas: Benefits beyond boundaries. Wallingford: $\mathrm{CABI}$. 
Chu, R.K.S., Choi, T. 2000. An importance-performance analysis of hotel selection factors in the Hong Kong hotel industry: a comparison of business and leisure travellers. Tourism Management 21, 363-377.

Deng, W. 2007. Using a revised importance-performance analysis approach: The case of Taiwanese hot springs tourism. Tourism Management 28 (5), 1274-1284.

Dobbs, K., Day, J., Skeat, H., Baldwin, J., Molloy, F., McCook, L., Johnson, M., Elliot, B., Skeat, A.., Vohland, K., Wachenfeld, D., Kenchington, R. 2010. Developing a long-term outlook for the Great Barrier Reef, Australia: A framework for adaptive management reporting underpinning an ecosystem-based management approach. Marine Policy 35 (2), 233-240.

Doucouliagos, H., Hall, J. 2010. Park visitation, constraints and satisfaction: a meta-analysis. School Working Paper, Faculty of Business and Law, Deakin University.

Duke, C.R., Persia, M.A. 1996. Importance-performance analysis of escorted tour evaluations. Journal of Travel and Tourism Marketing 5 (3), 207-23.

Dwyer, L., Kim, C. 2003. Destination competitiveness: determinants and indicators. Current Issues in Tourism 6 (5), 369-414.

Enright, M.J., Newton, J. 2004. Tourism destination competitiveness: a quantitative approach. Tourism Management 25 (6), 777-88.

Evans, M.R., Chon, K. 1989. Formulating and evaluating tourism policy using importanceperformance analysis. Hospitality Education and Research Journal 13 (3), 203-13.

Fitszimmons, C. 2007. Why Dive? Why Here ? A study of recreational diver enjoyment at a Fijian Eco-tourist resort. Proceedings of the 5th international Coastal and Marine Tourism Congress: Balancing marine tourism, development and sustainability. 11-15 September, Auckland, NZ.

Fletcher, D., Fletcher, H. 2003. Manageable Predictors of Park Visitor Satisfaction: Maintenance \& Personnel. Journal of Park \& Recreation Administration 21 (1), 21-37. 
GBRMPA 2007.

http://www.gbrmpa.gov.au/corp_site/info_services/media/media_archive/2007/2007_0 1_30.html (accessed March 2009).

Hoegh-Guldberg, H. 2008. Australian Tourism and Climate Change. Economic Strategies Pty Ltd.

Hollenhorst, S., Olson, D., Fortney, R. 1992. Use of importance-performance analysis to evaluate state park cabins: the case of the West Virginia state park system. Journal of Park and Recreation Administration 10 (1), 1-11.

Hutchings, P., Kingsford, M., Hoegh-Guldburg, O. 2008. The Great Barrier Reef: Biology, environment and management. CSIRO Publishing: Collingwood.

Huang, S. 2010. A Revised Importance-Performance Analysis of Tour Guide Performance in China. Tourism Analysis 15, 227-241.

Huan, T.C., Beaman, J., Shelby, L.B. 2002. Using action-grids in tourism management, Tourism Management 23, 255-264.

Hudson, S., Hudson, P., Miller, G.A. 2004. The measurement of service quality in the tour operating sector: a methodological comparison. Journal of Travel Research 42 (3), 305-312.

Huybers, T., Bennett, J. 2003. Environmental Management and the Competitiveness of Nature-Based Tourism Destinations. Environmental and Resource Economics 24, 213-233.

Kragt, M. E., Roebeling, P. C., Ruijs, A. 2009. Effects of Great Barrier Reef degradation on recreational reef-trip demand: a contingent behaviour approach. The Australian Journal of Agricultural and Resource Economics 53, 213-229.

Kumar, A., Olshavsky, R.W., King. M.F. 2001. Exploring alternative antecedents of customer delight. Journal of Consumer Satisfaction, dissatisfaction and complaining behaviour 14, 14-26. 
Leujak, W., Ormond, R. 2007. Visitor Perceptions and the shifting social carrying capacity of South Sinai's Coral Reefs. Environmental Management 39, 472-489.

Lück, M. (ed.) 2008. The Encyclopaedia of Tourism and Recreation in Marine Environments. $\mathrm{CABI}$, Wallingford, UK.

Matzler, K, Bailom, F., Hinterhuber, H., Renzl, B., Pichler, J. 2004. The asymmetric relationship between attribute-level performance and overall customer satisfaction: a reconsideration of the importance-performance analysis. Industrial Marketing Management 33, 271-277.

Mercer, P. 2010, 21 January. Australian scientists and industry tangled up in seaweed. The National. Retrieved on January 10, 2010 from $<w w w$. thenational.ae/apps/pbcs.dll/article?AID=/20100121/FOREIGN/701209811/1002/NE WS.>

Mikulić, J. and Prebežac, D. 2008. Prioritising improvement of service attributes using impact-range-performance analysis and impact asymmetry analysis. Managing Service Quality 18 (6), 559-576.

Mora, C. 2008. A clear human footprint in the coral reefs of the Caribbean. Proceedings of the Royal Society of Biology 275, 767-773.

Oh, H. 2001. Revisiting importance-performance analysis. Tourism Management 22 (6), 617-627.

Okello, M., D'Amour, D., Manka, S. 2008. Tourism attractions and satisfaction of Amboseli National Park, Kenya. Tourism Analysis 13 (4), 373-386.

Otto, J.E., Ritchie, J.R.B. 1996. The Service Experience in Tourism. Tourism Management 17(3), 165-174.

Pan, S., Ryan, C. 2007. Mountain areas and visitor usage - motivations and determinants of satisfaction; the case of Pirongia Forest Park, New Zealand. Journal of Sustainable Tourism 15 (3), 36-52. 
Pritchard, M., Havitz, M. 2006. Destination appraisal: an analysis of critical incidents. Annals of Tourism Research 33 (1), 25-46.

Roman, G., Dearden, P., Rollins, R. 2007. Application of Zoning and "Limits of Acceptable Change" to Manage Snorkelling Tourism. Environmental Management 39, 819-830.

Rudd, M.A. 2001. The non-extractive economic value of spiny lobster, Panulirus argus, in the Turks and Caicos Islands. Environmental Conservation 38, 226-234.

Rudd, M.A., Tupper, M.H. 2002. The impact of Nassau grouper size and abundance on scuba diver site selection and MPA economics. Coastal Management 30, 133-151.

Ryan, C. 1995. Researching tourist satisfaction: Issues, concepts, problems. London: Routledge.

Ryan, C. 2003. Recreational Tourism. Clevedon, Channel View Publications.

Ryan, C., Cessford, G. 2003. Developing a Visitor Satisfaction Monitoring Methodology: Quality Gaps, Crowding and Some Results. Current Issues in Tourism 6 (6), 457-507.

Ryan, C., Huyton, J. 2002. Tourism and Aboriginal people. Annals of Tourism Research 29 (3), 631-647.

Tonge, J., Moore, S.A. 2007. Importance-satisfaction analysis for marine-park hinterlands: a Western Australian case study. Tourism Management 28 (3), 768-776.

Tyrrell, T., Okrant, M. 2004. Importance-Performance Analysis: Some recommendations from an economic planning perspective. Tourism Analysis 9, 1-14.

Uysal, M., Howard, G., Jamrozy, U. 1991. An application of importance-performance analysis to a ski resort: a case study in North Carolina. Visions in Leisure and Business 10, 16-25.

Uyarra, M, Cote, I., Gill, J., Tinch, R. Viner, D., Watkinson, A. 2005. Island-specific preferences of tourists for environmental features: implications of climate change for tourism-dependent states. Environmental Conservation 32 (1), 11-19. 
Uyarra, M. C., Watkinson, A. R., Cote, I. M. 2009. Managing Dive Tourism for the Sustainable Use of Coral Reefs: Validating Diver Perceptions of Attractive Site Features. Environmental Management 43, 1-16.

Wade, D.J. \& Eagles, P. 2003. The use of importance-performance analysis and market segmentation for tourism management in parks and protected areas: an application to Tanzania's National Parks. Journal of Ecotourism 2 (3), 196-212.

Weber, K. 2000. Meeting planners' perceptions of hotel-chain practices and benefits: an importance-performance analysis. Cornell Hotel and Restaurant Administration Quarterly 41(1), 32-8.

Wilson, R., Turton, S. 2009. Cairns Case Study. In S.Turton, W. Hadwen \& R. Wilson (eds). The Impacts of Climate Change on Australian Tourism Destinations: developing adaptation and response strategies -- a scoping study. CRC Sustainable Tourism, Gold Coast.

Zhang, H.Q., Chow, I. 2004. Application of importance-performance model in tour guides" performance: evidence from mainland Chinese outbound visitors in Hong Kong. Tourism Management 25, 81-91. 